\title{
Geography - Geographic Analysis and Monitoring Program
}

\section{Famine Early Warning System Network (FEWS NET)}

The FEWS NET mission is to identify potentially food-insecure conditions early through the provision of timely and analytical hazard and vulnerability information. U.S. Government decision-makers act on this information to authorize mitigation and response activities. The U.S. Geological Survey (USGS) FEWS NET provides tools and data for monitoring and forecasting the incidence of drought and flooding to identify shocks to the food supply system that could lead to famine. Historically focused on Africa, the scope of the network has expanded to be global coverage.

FEWS NET implementing partners include the USGS, National Aeronautics and Space Administration (NASA), National Oceanic and Atmospheric Administration (NOAA), United States Agency for International Development (USAID), United States Department of Agriculture (USDA), and Chemonics International.

\section{Agro-meteorological Monitoring}

Crop monitoring efforts at the USGS Center for Earth Resources Observation and Science (EROS) use the calculation of a Water Requirement Satisfaction Index (WRSI). WRSI is a spatially explicit index that provides an indication of crop performance based on the water supply and demand that a crop experiences during the growing season.

Inputs to the WRSI calculation include satellite rainfall estimates, potential evapotranspiration, water holding capacity of the soil, crop type, start of season, and length of growing season. The image below shows the results of the WRSI calculation for maize in southern Africa, early in the 2003-2004 season. Shades of green indicate average to above average crop conditions. Yellow and tan colors designate mediocre to poor conditions, while other areas indicate either a late start to the growing season (pink) or areas that are yet to start (cyan).

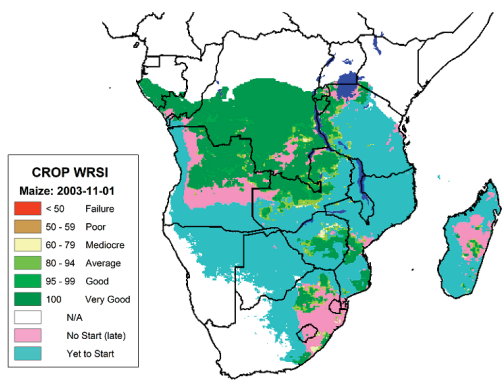

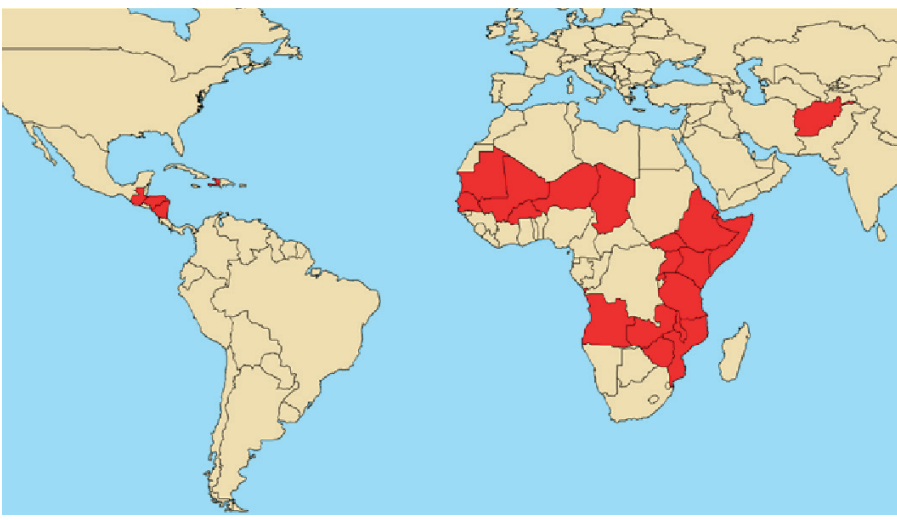

FEWS NET currently supports data collection and analysis in 20 African countries, Afghanistan, Guatemala, Honduras, Nicaragua, and Haiti.

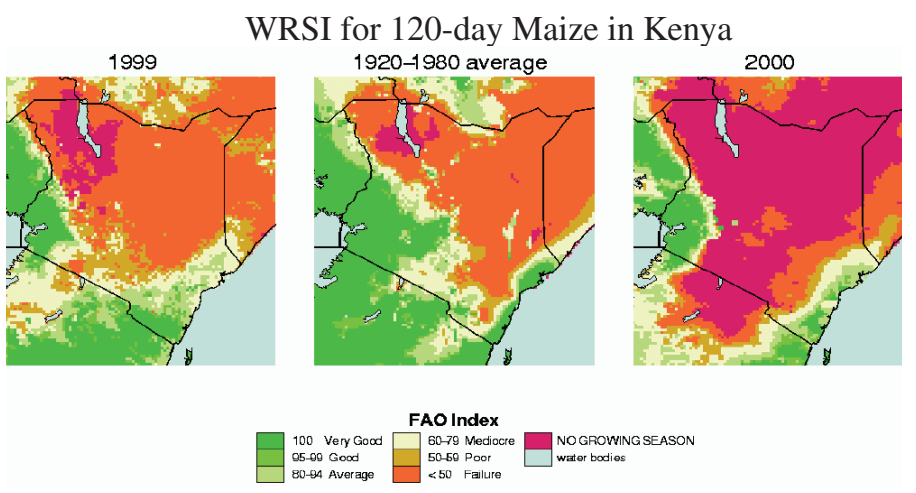

Drought conditions, which plagued much of the Horn of Africa in 2000, also severely affected maize growing regions of Kenya, as evidenced in these WRSI comparisons for 1999, long-term average, and 2000.

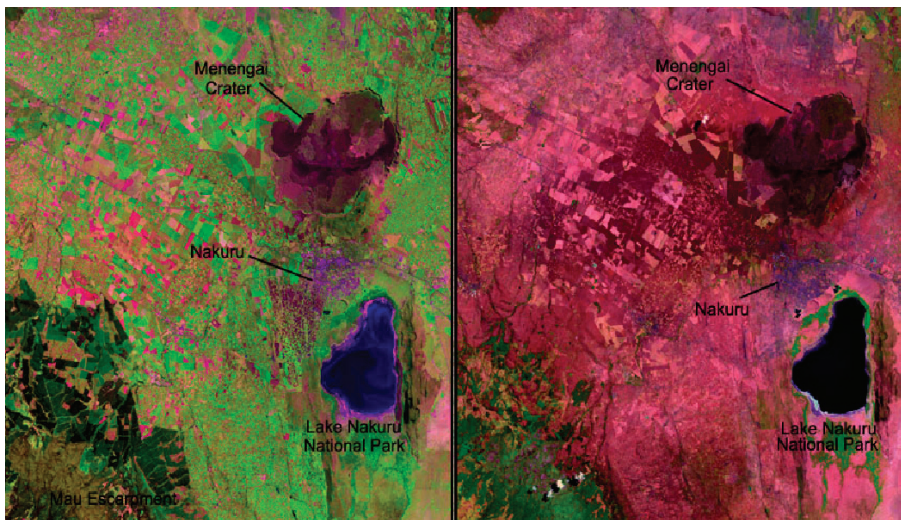

These Landsat images show agricultural conditions in Kenya during a year of good rains (left) and the drought of 2000 (right). Light green parcels are fields of healthy crops, and dark green parcels are tea plantations. Pink tones are associated with bare soil. 


\section{Flood Hazard Monitoring and Forecasting}

USGS EROS flood modeling efforts involve the implementation of a stream flow model that uses estimated and forecast precipitation, potential evapotranspiration, land cover, soil type, and digital elevation model (DEM) derivatives. Land cover and DEM data sets are created at the USGS EROS.

In addition to forecasting the likelihood of flood occurrence, USGS FEWS NET seeks to highlight areas at risk through the use of inundation mapping. The objectives of the flood inundation mapping are twofold: to determine which localities are at risk of flooding given river levels and to determine the location of safe zones where populations could move to avoid loss of life and property.

\section{Africa Weather Hazards Assessment}

FEWS NET partners and field staff from North America and Africa participate in a weekly online meeting to assess current and potential hazard areas for Africa, Afghanistan, and Central America. Hazard areas are those regions where inadequate moisture for seasonal crops or excessive moisture/flooding threatens food security and local livelihoods. A weekly hazard assessment map is produced based on numerous remotely sensed and meteorological products.

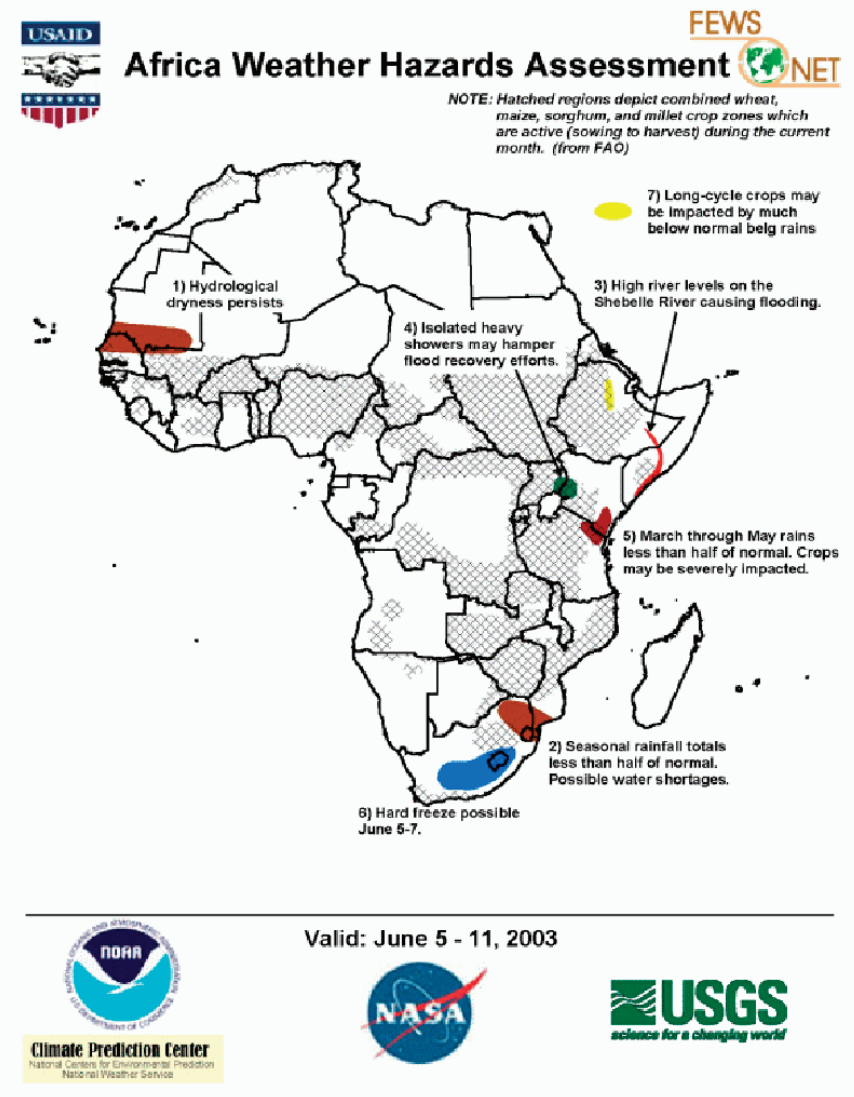

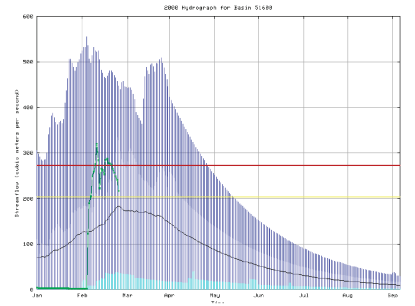

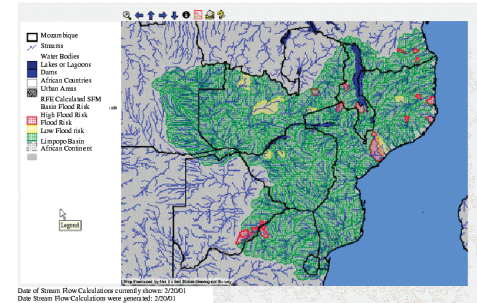

Hydrographs created from model outputs are used to monitor stream flows and create basin-level flood risk maps.
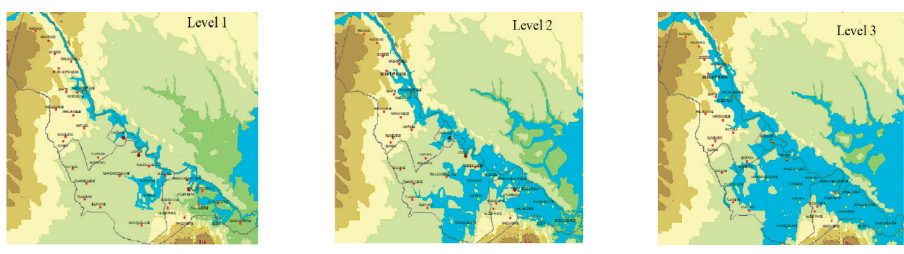

This series of inundation maps shows the varied spatial extent of flooding for the Chokwe district of Mozambique, based on stream gage levels of 4-6 (Level 1), 6-8 (Level 2), and 8-10 (Level 3) meters.

\section{For More Information}

Africa Data Dissemination Service (ADDS) Web page:

http://earlywarning.usgs.gov/adds

\section{Other FEWS NET links:}

http://earlywarning.usgs.gov/afghan http://earlywarning.usgs.gov/centralamerica http://earlywarning.usgs.gov/haiti

James P. Verdin, Ph.D.

USGS Center for Earth Resources

Observation and Science (EROS)

Mundt Federal Building

Sioux Falls, South Dakota 57198

Email: verdin@usgs.gov 